\title{
Calculation method for the effect of heat rejection of split-type air conditioner on thermal environment and building energy demand for neighbourhood-level
}

\author{
Haijing Liu ${ }^{1}$, Yiqun Pan ${ }^{1, *}$, and Zhizhong Huang ${ }^{2}$ \\ ${ }^{1}$ Department of Mechanical and Energy Engineering, Tongji University, Shanghai 201804, China \\ ${ }^{2}$ Sino-German College of Applied Sciences, Tongji University, Shanghai 201804, China
}

\begin{abstract}
The purpose of this research is to propose a simple and fast method to evaluate the effect of heat rejection of split-type air conditioner on the thermal environment surrounding the building and the building cooling demand to provide guidance for architectural design in the urban planning stage. In this paper, we first determined the factors that affect or are affected by heat rejection as heat dissipation, wind speed, and ambient air temperature, which as inputs to the CFD to build the regression model of the temperature rise. Then, the regression model is coupled with the energy consumption simulation software EnergyPlus to estimate the building cooling increase. The result of taking a typical residential building as a reference show that the maximum temperature rise and cooling demand increase with the values of $1.86^{\circ} \mathrm{C}$ and $17 \%$.
\end{abstract}

Keywords: Heat rejection; Ambient temperature; Wind speed; Building cooling energy.

\section{Introduction}

Recent years have been a significantly increase in building energy requirement for developing of the urbanization and improving requirements for thermal comfort [1,2]. At the urban or neighbourhood level, considering the buildings in urban context more important than regrading them as stand-alone for accurately predicting building energy demand [3]. Especially for the summer, the heat island effect in cities has been severely deteriorated with worsening thermal environment by the continuous growth of building energy consumption [4]. Furthermore, the deteriorating thermal environment affect the city buildings by increasing the energy consumption and electric power necessary for cooling needs [5]. Consequently, there is a vicious circle between the built-environment and building energy consumption, and heat rejection from the air-conditioner is the main way of building energy demand. To deal with this situation, scholars have focused on air conditioners energy consumption to reduce this consumption and increase energyefficiency to make the urban environment better.

\footnotetext{
*Corresponding author: yiqunpan@tongji.edu.cn
} 
Because of the advantages of simple structure, flexible operation, and smooth appearance, split-type air conditioners are broadly applied in households and offices. Splittype air conditioners take in air near the condenser and reject heat to the outside with a fan, which is a process of sensible heating; that is, heat is added to the air without changing its relative humidity [6]. A stream of studies has been explored on factors that affect the heat rejection of air conditioners, mitigate strategies to reduce heat rejection, and its effect on thermal environment and building energy consumption.

As we all known, heat rejection from the fan is equals to the building load and the power consumption of the air conditioner, which can be obtained from the building load and the COP (coefficient of Performance, used to calculate the power consumption of the unit). The wind that has a significant effect for the accumulation of the heat from the fan near the building under the condition that the heat rejection and outdoor ambient temperature are kept constant [7]. Chun-Ming Hsieh proposed that the specific installation location of the outdoor unit is every floor or every third floor of the building to reduce the impact of the heat rejection on the thermal environment and building load [8].

Heat rejection from the fan generate a rise for the ambient air temperature rise near the fan surrounding the building that affects the performance of air conditioner and the building cooling demand. With the higher temperature around the outdoor condenser unit, more energy consumption of the air conditioner will produce [9]. Temperature rise adjacent to the building envelope affected by the location of the condenser unit where the highest can reach by $3.1^{\circ} \mathrm{C}$ in Wuhan at 14:00 for an office building [7]. Coupling CFD and EnergyPlus, Chun-Ming Hsieh [10] argued that the temperature rise can increase $1.89^{\circ} \mathrm{C}$ surrounding the building which cause and additional $10 \%$ for the building cooling demand for a typical high-rise residential building in Taiwan in summer night.

The previous studies that heat rejection of split-type air conditioners are based on the built architecture, which obviously does not take the heat reject for the building or the buildings on a neighbourhood-level in the planning stage into account. In addition, the time scale from the above research is short so that the evaluation of heat rejection on the environment and building energy in the whole summer cannot available. To deal with these tricky, we propose a simple, convenient, and fast calculation method that build a regression model for the temperature rise, and then obtain the building cooling demand increase by revising the original weather data used as inputs to energy simulation software.

\section{Methodology}

This research establishes a regression model with numerical simulation in CFD used to revise the original weather data for building energy simulation and calculation to predict the impact of heat reject on a long-term scale. The research process can be schematized into the following steps:

1) propose the assumption that the heat rejection of the air conditioner is equivalent to the heat dissipation from four walls of the building;

2) design numerical simulation cases based on the factors that affect the heat rejection and their variation range;

3) establish a regression model of the temperature rise (described by dT) according to the above calculation results;

4) calculate the effect of heat rejection on thermal environment and building cooling energy demand for a typical residential building. 


\subsection{Assumption}

The weather file, where the parameters such as temperature, humidity, and solar radiation are the constant values that change over time is used for building energy consumption simulation. The temperature rise caused by heat reject just increase the partial temperature that needs to be processed, for example, to make an average, to get the effects on thermal environment and building energy demand. We argue that the temperature rises from heat rejection of the condenser units is distribute uniformly in the air adjacent to building envelope on the neighbourhood level. Based on the above, we propose the assumption that the heat rejection is equal to the heat dissipation of the four walls of the building, which is calculated as equation (1):

$$
\mathrm{Qw}=(1+\mathrm{COP}) / \mathrm{COP} * \mathrm{Qc} * \mathrm{Sc} / \mathrm{Sw}
$$

Where: Qw is the heat dissipation of the wall, $\mathrm{W} / \mathrm{m}^{2}$; $\mathrm{COP}$ is the coefficient of performance of the split-type air conditioner; Qc is the building cooling load, $\mathrm{W} / \mathrm{m}^{2}$; Sc is the net conditioned area, $\mathrm{m}^{2} ; \mathrm{Sw}$ is the wall surface area, $\mathrm{m}^{2}$.

\subsection{Inputs parameters and range for CFD}

We have already known that heat rejection is a basic influencing factor depend on the building cooling energy demand will be as the first input for the CFD, described as Qw. The wind speed that affect the temperature rise of the air adjacent to the building envelope is critical from the previous studies as the second input, described as $\mathrm{V}_{0}$. Besides, the ambient air temperature influenced by the temperature rise is the third input, described as Ta.

\subsubsection{The value of $\mathrm{Qw}$}

According to equation (1), the value of Qw that related to the COP, building cooling load, building cooling area, and building wall area is determined. For a special air conditioner, the COP is a constant, the building cooling load is calculated from the EnergyPlus with the original weather file, and the other two parameters, building cooling area and building wall area, need to be defined.

The length and width of the building used to the numerical simulation are the same $30 \mathrm{~m}$ that avoid the influence of wind direction on the temperature rise for different side of the wall and consider the problem of the temperature rise values of the air adjacent to the building envelope. The building height of building is $100 \mathrm{~m}$ for the same reason of the values.

The COP of the air conditioner used in this research is 2.8. There are four levels for cooling energy load on the basis of empirical analysis, which are $20 \mathrm{~W} / \mathrm{m}^{2}, 50 \mathrm{~W} / \mathrm{m}^{2}, 100 \mathrm{~W} /$ $\mathrm{m}^{2}$, and $150 \mathrm{~W} / \mathrm{m}^{2}$. As a result, the heat dissipation of the wall is $67.6 \mathrm{~W} / \mathrm{m}^{2}, 169 \mathrm{~W} / \mathrm{m}^{2}$, $339 \mathrm{~W} / \mathrm{m}^{2}$, and $508 \mathrm{~W} / \mathrm{m}^{2}$.

\subsubsection{The value of $\mathrm{V}_{0}$}

The value of wind speed is also four levels referring to wind speed frequency chart of weather file in Shanghai (Fig.1), which is $0 \mathrm{~m} / \mathrm{s}, 1 \mathrm{~m} / \mathrm{s}, 3 \mathrm{~m} / \mathrm{s}$, and $5 \mathrm{~m} / \mathrm{s}$. 


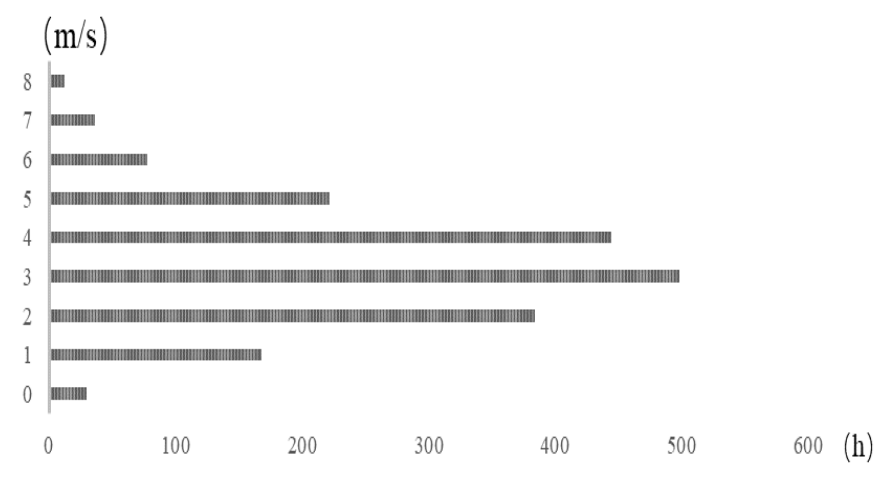

Fig. 1. Frequency chart of wind speed in Shanghai.

\subsubsection{The value of $\mathrm{Ta}$}

Based on the set temperature of the air conditioner is $26^{\circ} \mathrm{C}$, the value of Ta takes a total of 13 levels that ranges from 28 to $40^{\circ} \mathrm{C}$ for each degree.

Then, we arrange the values of the three input variables and get the total calculation cases. In summary, the values for inputs parameters in the CFD and the total number of cases are as shown in Table1.

Table 1. Setting input parameters and their range.

\begin{tabular}{|c|c|c|c|}
\hline Qw $\left(\mathbf{W} / \mathbf{m}^{2}\right)$ & $\mathrm{Ta}\left({ }^{\circ} \mathbf{C}\right)$ & $\mathbf{V}_{\mathbf{0}}(\mathbf{m} / \mathbf{s})$ & Cases \\
\hline & 28 & & \\
& 29 & & \\
& 30 & & \\
& 31 & & \\
67.6 & 32 & 0 & \\
169 & 33 & 1 & \\
339 & 34 & 3 & \\
508 & 35 & 5 & \\
& 36 & & \\
& 37 & & \\
& 38 & & \\
& 49 & & \\
\hline
\end{tabular}

\subsection{Boundary conditions in Fluent}

The length of the fluid field is $4 \mathrm{H}+$ Block field $+10 \mathrm{H}$; the width is $5 \mathrm{H}+$ Block field $+5 \mathrm{H}$; and the height is $6 \mathrm{H}$, where $\mathrm{H}$ is building's height. The sets of boundary condition in Fluent as shown in Table2.

Table 2. Boundary conditions for Fluent.

\begin{tabular}{|c|c|}
\hline Turbulence model & Steady standard k-e model \\
\hline Momentum & First order upwind \\
\hline Turbulent kinetic energy & First order upwind \\
\hline Turbulent dissipation energy & First order upwind \\
\hline
\end{tabular}


The inlet for the model is velocity inlet where the distribution of the wind speed profile is set on the basis of law of exponents in the height, as shown in equation (2).

$$
\mathrm{V} / \mathrm{V}_{0}=\left(\mathrm{Z}+\mathrm{Z}_{0}\right)^{\mathrm{a}}
$$

where, $v$ is the wind speed at height $Z, \mathrm{~m} / \mathrm{s} ; \mathrm{V}_{0}$ is the wind speed at the reference height $\mathrm{Z}_{0}$, which is also the value to put into the Fluent in this article, $\mathrm{m} / \mathrm{s} ; \mathrm{Z}$ is the height, $\mathrm{m} ; \mathrm{Z}_{0}$ is the reference height, $10 \mathrm{~m}$ away from the ground; $a$ is the ground roughness index, where takes the value of 0.28 according to the urban land use.

\subsection{Value of numerical simulation results}

The value method of numerical simulation results is very critical, which determines the accurate description of the impact of heat rejection on the thermal environment around a building. The temperature rise (dT) of this research is the average air temperature rise of the second grid layer at a distance of $0.5 \mathrm{~m}$ adjacent to the building surface, and the specific points are shown in Figure 2.
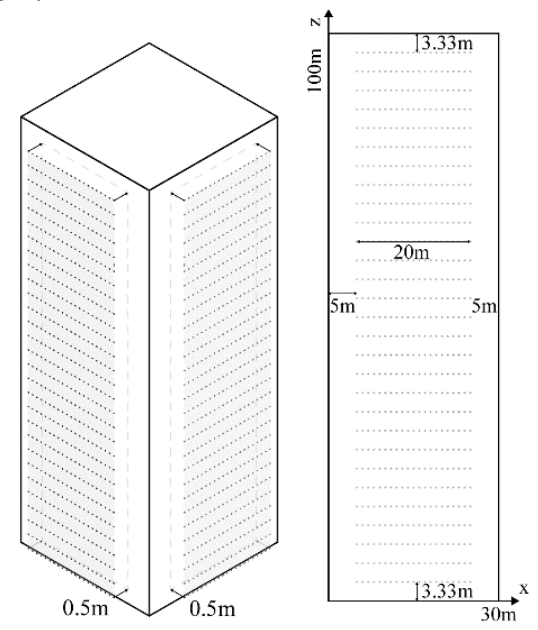

Fig. 2. Point location of simulation result.

From the figure 2, we can see 20 points are taken in the middle every one meter to avoid edge effect for each wall in the horizontal direction, and the range of result points in the vertical direction is from $3 \mathrm{~m}$ to $96 \mathrm{~m}$ every $3 \mathrm{~m}$.

\subsection{Typical residential building design model}

The regression model of temperature rise will replace numerical simulation to calculate the impact of heat rejection on the thermal environment surrounding the building. Taking a typical residential building as a reference, we calculate the cooling load firstly with the original weather data in EnergyPlus that used to calculate the temperature rise to get the revised weather file for again calculate the cooling load. Then, the cooling energy increase could get from the building energy consumption simulation with different weather file. As we can see, there is a loop calculation between the heat rejection and building energy cooling, and the condition for the end of the loop is that the percentage of energy increase is less than $0.5 \%$ compared with the previous calculation. 

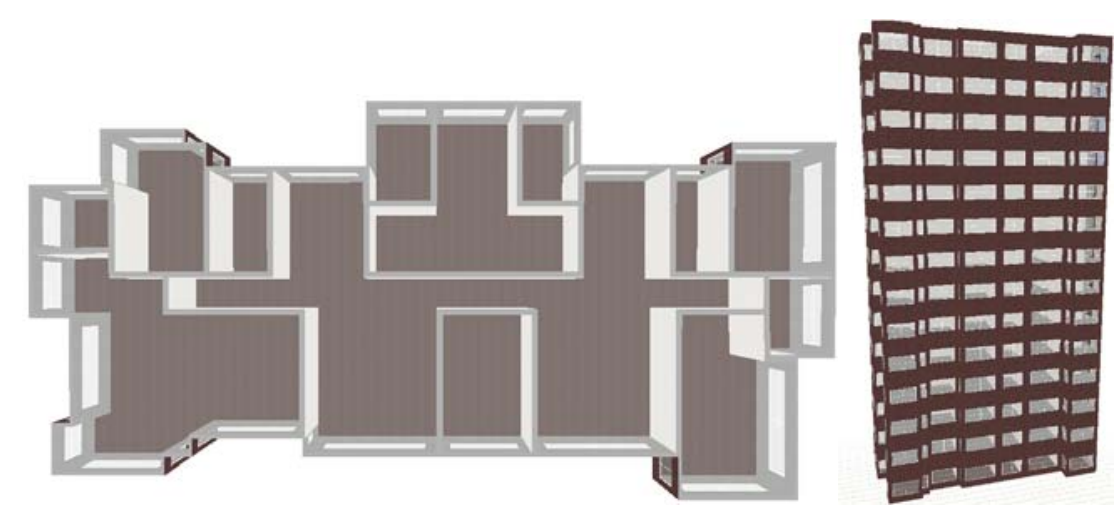

Fig. 3. Floor plans and elevations of the typical building.

A typical 14-story residential building in Shanghai of China was used to calculate the impact of heat rejection on temperature rise adjacent to the building envelope and building cooling energy increase adopting the regression model. The setting of thermal parameters of the external walls, windows and roofs, and internal heat gains of equipment, lighting and people takes local building energy efficiency design standards as a reference.

\section{Results}

\subsection{Results of the numerical simulation}

The results of temperature rise under different inputs as shown in Figure 4 that have been handled from Fluent.

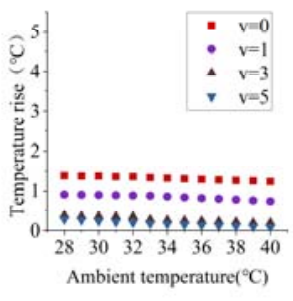

$\mathrm{Qw}=67.6 \mathrm{~W} / \mathrm{m}^{2}$

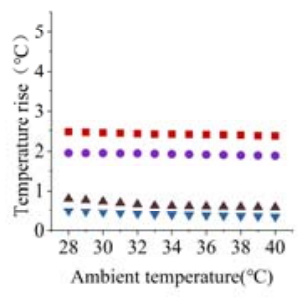

$\mathrm{Qw}=169 \mathrm{~W} / \mathrm{m}^{2}$

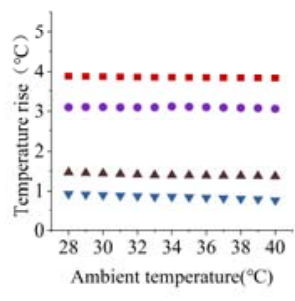

$\mathrm{Qw}=339 \mathrm{~W} / \mathrm{m}^{2}$

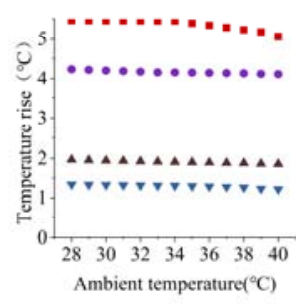

$\mathrm{Qw}=508 \mathrm{~W} / \mathrm{m}^{2}$

Fig. 4. Results of temperature rise under different inputs.

As discussed above, heat dissipation of the wall is the primarily factor to cause the temperature rise and wind speed plays a key role to dissipate heat and reduce heat island, which can be clearly seen from Figure 4 . The maximum temperature rise is $5.46^{\circ} \mathrm{C}$ when heat dissipation of wall is $508 \mathrm{~W} / \mathrm{m}^{2}$ and wind speed is $0 \mathrm{~m} / \mathrm{s}$, and the minimum is $0.08^{\circ} \mathrm{C}$ under the condition that heat dissipation is $67.6 \mathrm{~W} / \mathrm{m}^{2}$ and wind speed is $5 \mathrm{~m} / \mathrm{s}$.

\subsection{Establish regression model}

In this paper, SPSS (Statistical Product and Service Solution) is used to build the regression model between the inputs of heat dissipation of wall, ambient air temperature, and wind speed and the output of temperature rise, as shown in equation (3). 


$$
\mathrm{dT}=1.914-0.0118 * \mathrm{Ta}+0.00569 * \mathrm{Qw}-0.526 * \mathrm{~V}_{0}
$$

The adjusted R-square of this model is 0.88 , which means that $88 \%$ of the dependent variable are explained by the independent variables; and the F value is 489 meaning the hypothesis test has passed, so the model has certain credibility.

\subsection{Results of heat rejection on thermal environment and building cooling energy demand}

The effect of heat rejection on the layer adjacent to the building envelope and cooling energy demand of the building was iteratively calculated using the above model and EnergyPlus. We call the simulation with the original weather file as the first calculation, and a total of three calculations have reached the convergence condition described in 2.5. The hourly temperature rise and cooling energy increase that got from the last calculation is shown in Figure 5 and Figure 6.

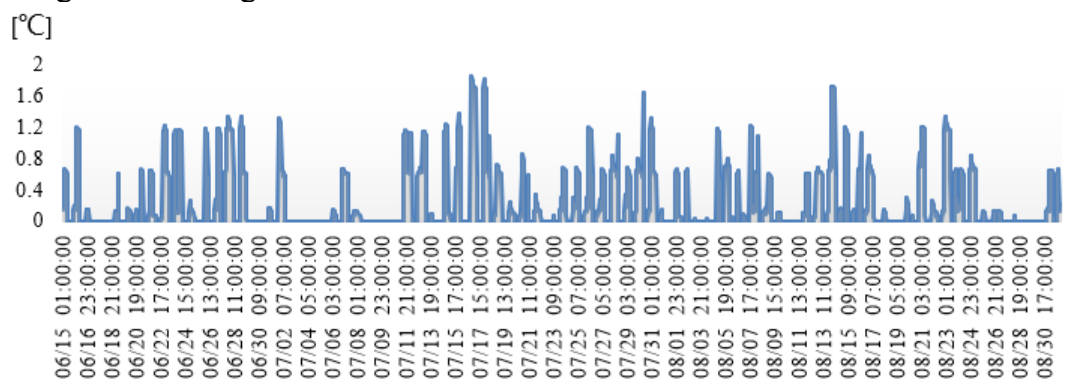

Fig. 5. Hourly temperature rise caused by the heat rejection.

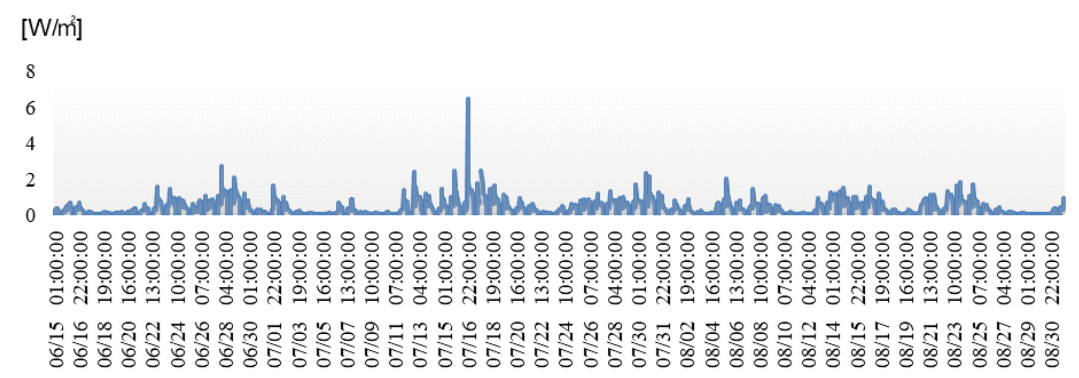

Fig. 6. Hourly cooling energy demand increase caused by the heat rejection.

The hourly temperature rise surrounding the building is diverse can be seen from the Figure 5 due to the inputs, resulting cooling energy increase to change over time. The maximum temperature rise is $1.86^{\circ} \mathrm{C}$, and the average is $0.2^{\circ} \mathrm{C}$. The maximum cooling energy increase is $6.96 \mathrm{~W} / \mathrm{m}^{2}$, which is an increase of $17 \%$ compared to the cooling energy with the original weather data, and the total cooling increase is $0.53 \mathrm{kWh} / \mathrm{m}^{2}$.

\section{Conclusion}

With the increasing urbanization and building energy demand, the built environment has become particularly important no matter for the prediction of building energy demand or reduction of heat island. This paper proposes a novel calculation method for the impact of heat rejection on the thermal environment and building cooling demand on a large spatial 
and long-time scale. A regression model for calculating the temperature rise is established with the numerical simulation on the basis of heat rejection of air conditioner is equivalent to the heat dissipation of wall. The coupled calculation method of the model and EnergyPlus results in a typical residential building with a temperature rise of up to $1.86^{\circ} \mathrm{C}$ and a cooling load increase of $17 \%$.

It is reasonable and referential to use the model to evaluate the impact of heat rejection of split-type conditioners on the thermal environment surrounding the building and the cooling demand of the building on a neighbourhood scale. It is meaningful to study the impact of heat rejection, which can be used in the building plan and design stage to provide advice for better environment and lower energy consumption. Besides, there are still some uncertainties that may affect the results, such as the value of COP, which is a constant of 2.8 and further research is encouraged to analyse its impact on the results.

\section{References}

1. Building energy conservation research centre, Tsinghua University. 2019 AnnualReport on China Building Energy Efficiency. Beijing: China Architecture \& BuildingPress; 2019 [in Chinese].

2. United Nations. World Urbanization Prospects: The 2018 Revision<https://population.un.org/wup/Country-Profiles/> [accessed June 2, 2019].

3. Yilong Han, John E. Taylor, Anna Laura Pisello. Exploring mutual shading and mutual reflection inter-building effects on building energy performance. Applied Energy 185 (2017) 1556-1564.

4. Hsieh C-M, Aramaki T, Hanaki K. 2007. The feedback of heat rejection to air conditioning load during the nighttime in subtropical climate. Energy and Building. 39: 1175-1182.

5. Xiaoshan Yang, Lilliana L.H.Peng, Zhidian Jiang. Impact of urban heat island on energy demand in buildings: Local climate zones in Nanjing. Applied Energy 260(2020) 114279.

6. A.S. Adelia, C. Yuan, L. Liu, R.Q. Shan. Effects of urban morphology on anthropogenic heat dispersion in tropical high-density residential areas. Energy \& Buildings 186 (2019) 368-383.

7. Mengtao Han, Hong Chen. Effect of external air-conditioner units' heat release modes and positions on energy consumption in large public buildings[J]. Building and Environment 111 (2017) 47e60.

8. Chun-Ming Hsieh, Toshiya Aramaki, Keisuke Hanaki. Managing heat rejected from air conditioning systems to save energy and improve the microclimates of residential buildings. Computers, Environment and Urban Systems 35 (2011) 358-367.

9. M. Bojic, M. Lee, F. Yik, Influence of a depth of a recessed space to flow due to airconditioner heat rejection, Energy Build. 34 (2002) 33e43.

10. Hsieh C-M, Aramaki T, Hanaki K. 2007. The feedback of heat rejection to air conditioning load during the nighttime in subtropical climate. Energy and Building. 39: $1175-1182$. 